\title{
Some alternative fuels for C.I. engines
}

\section{SAUMYA SHUKLA, R. KHOLE PRIYANKA AND V.P. JOSHI}

Received : 07.04.2017; Revised : 05.09.2017; Accepted : 20.09.2017

See end of the Paper for authors' affiliation

Correspondence to :

SAUMYA SHUKLA

Department of Farm Machinery and Power, Junagadh Agricultural University, JUNAGADH (GUJARAT) INDIA

Email : saumyashuklalk@ gmail. com
- ABSTRACT : Today the diesel engine is a very important prime mover, being used in buses, trucks, locomotives, tractors, pump sets and other stationary industrial applications, small and medium electric power generation and marine propulsion. These wide fields of global usage of diesel engines lead to ever increasing demand of petroleum derived fuels. Today the world is facing three critical problems: high fuel prices, climatic changes, and air pollution. These and other environmental disasters have brought about demands for alternative fuels and energy sources that are convenient, environmentally friendly and economically viable. In recent years, the prominence to conserve petroleum based fuels has provided the motivation for several studies on the development and testing of alternate fuels in diesel engine. This study takes a critical look on the review of already existing alternative fuels that produce less emission or no emission at all. The advantages of the alternative fuels are highlighted and exhaustively discussed. The engine performance and emission characteristics are also discussed.

- KEY WORDS : C.I. engines, Alternative fuels, Environmental characteristics, Performance characteristics, Emission characteristics

- HOW TO CITE THIS PAPER : Shukla, Saumya, Priyanka, R. Khole and Joshi, V.P. (2017). Some alternative fuels for C.I. engines. Internat. J. Agric. Engg., 10(2) : 595-601, DOI: 10.15740/HAS/ IJAE/10.2/595-601. 